\title{
Pork barrel as a signaling tool: the case of US environmental policy
}

\author{
Hélia Costa
}

February 2016

Centre for Climate Change Economics and Policy Working Paper No. 255

Grantham Research Institute on Climate Change and the Environment Working Paper No. 225 
The Centre for Climate Change Economics and Policy (CCCEP) was established by the University of Leeds and the London School of Economics and Political Science in 2008 to advance public and private action on climate change through innovative, rigorous research. The Centre is funded by the UK Economic and Social Research Council. Its second phase started in 2013 and there are five integrated research themes:

1. Understanding green growth and climate-compatible development

2. Advancing climate finance and investment

3. Evaluating the performance of climate policies

4. Managing climate risks and uncertainties and strengthening climate services

5. Enabling rapid transitions in mitigation and adaptation

More information about the Centre for Climate Change Economics and Policy can be found at: http://www.cccep.ac.uk.

The Grantham Research Institute on Climate Change and the Environment was established by the London School of Economics and Political Science in 2008 to bring together international expertise on economics, finance, geography, the environment, international development and political economy to create a worldleading centre for policy-relevant research and training. The Institute is funded by the Grantham Foundation for the Protection of the Environment and the Global Green Growth Institute. It has nine research programmes:

1. Adaptation and development

2. Carbon trading and finance

3. Ecosystems, resources and the natural environment

4. Energy, technology and trade

5. Future generations and social justice

6. Growth and the economy

7. International environmental negotiations

8. Modelling and decision making

9. Private sector adaptation, risk and insurance

More information about the Grantham Research Institute on Climate Change and the Environment can be found at: http://www.Ise.ac.uk/grantham.

This working paper is intended to stimulate discussion within the research community and among users of research, and its content may have been submitted for publication in academic journals. It has been reviewed by at least one internal referee before publication. The views expressed in this paper represent those of the author(s) and do not necessarily represent those of the host institutions or funders. 


\title{
Pork Barrel as a Signaling Tool: The Case of US Environmental Policy*
}

\author{
Hélia Costa \\ Grantham Research Institute and LSE Cities \\ London School of Economics ${ }^{\dagger}$
}

February 2016

\begin{abstract}
Are environmental policies affected by the political cycle? This paper investigates if environmental spending is used as pork barrel with signaling purposes. It develops a two-period model of electoral competition where politicians use current policies to signal their preferences to rational, forward-looking voters. There exists an equilibrium where incumbents use pork barrel spending for signaling in majoritarian systems. Results show that it is directed towards ideologically homogeneous groups, and is mitigated if the incumbent is a "lame duck" or has a high discount rate. The predictions of the model are tested using data on US state level environmental expenditures. The empirical results show support for the signaling motive as a central mechanism in generating pork barrel towards the environment.
\end{abstract}

JEL classification: D72, H76, Q58, C23

Keywords: Electoral Competition, Environmental Spending, Pork Barrel, Signaling

*I thank Jérôme Adda, Stefano Carratini, Goreti Faria, Niall Hughes, Andrea Mattozzi, Massimo Morelli, Marek Raczko, Jenifer Ruiz-Valenzuela, Gerhard Toews, and participants at the GRI and OxCarre seminars and 2015 EAERE conference for valuable comments. All remaining errors are my own. I acknowledge the support of the Portuguese Science and Technology Foundation (FCT) under grant with reference SFRH/BD/60628/2009 and funding from the the ESRC Centre for Climate Change Economics and Policy.

${ }^{\dagger}$ Email: h.costa@lse.ac.uk 


\section{Introduction}

It is a well documented fact that economic decisions, across a variety of issues, are distorted by electoral competition. ${ }^{1}$ One particular tool used by politicians in order to obtain political advantage is the assignment of benefits to particular groups, geographically or otherwise determined. These benefits, typically called pork barrel ${ }^{2}$ might take the form of increases in highly visible local public goods, approval of particular projects, or even transfers from the central government. Pork barrel is often used in legislatures as a "currency" to build coalitions that allow to pass general interest legislation, but it is also an instrument in electoral competition used by incumbent politicians to gain the voters' support. And while in the former case it might generate benefits, by greasing the wheels of the legislative process (Evans, 2004), election-motivated changes in the composition of spending are widely accepted as constituting efficiency losses: by distributing pork when the budget is limited and fixed, politicians deviate from the welfare maximizing level of collective goods (Hicken and Simmons, 2008). Assessing the mechanism that is behind them, and the incentives to perform these policies is, therefore, of significant importance.

This paper aims at providing an insight into the mechanism generating election-year pork barrel policies, by deriving theoretical implications from a simple model and testing them empirically. The focus is on environmental spending decisions, which are likely to have strong support from some citizens, but not others. It evaluates whether signaling is a driving force behind pre-electoral pork, where signaling refers to the conveying of a preference for the environment by the politician, true or not, through enacted policies. The idea is that politicians cannot commit to implement policies that they do not favor, and in the absence of this commitment, they use current policies to signal preferences, which are persistent over time, to the electorate. The implications of the model are tested on United States (US) environmental policy. Environmental policy has gained an important role in the American political landscape (Hillstrom and Hillstrom, 2010), and the environment has been defended as a pivotal issue, particularly in state and local elections (Lake, 1983 and Udall, 1987). The fact that it triggers strong opinions from the electorate renders it particularly suitable to test the current model.

A two-period model of electoral competition is developed, based on the

\footnotetext{
${ }^{1}$ See Brender and Drazen (2005) for an empirical study on a large panel of countries.

${ }^{2}$ The expression is said to have originated in the pre civil war United States, when barrels of salt pork were given to slaves, who were required to compete for a share of it.
} 
framework of Persson and Tabellini (1999), where an incumbent divides a fixed budget between a national public good and expenditures on three "particularistic" issues - one of which is environmental spending - that assign extra benefits for those voters with strong preferences for them. Here, however, the politician is both policy and office motivated, and there is no commitment. Politicians are citizens who have themselves preferences for different types of expenditures. Thus the incumbent in the first period chooses her policy so as to maximize her utility, which depends on her policy preferences and the probability of being re-elected. Voters are rational, forward-looking, and informed about economic policies but imperfectly informed about the preferences of the politician. So they use current policies to infer them through bayesian updating: an increase in expenditures might mean the politician is performing pork barrel or that she has a genuine preference for them. The concept of probabilistic voting is used to solve the model. Finally, all agents are also ideologically biased.

The model generates conditions under which pork barrel arises as a political equilibrium for signaling purposes, that is, when pork is credible or effective in changing imperfectly informed voters' beliefs. Results show that this occurs less when the politician's discount factor is higher than a threshold, and when she cannot be re-elected (she is a "lame duck"). These findings are consistent with previous results of Downsian models (Downs, 1957). The former occurs because a high discount rate decreases the incentives of an incumbent to seek re-election through pork. So for example establishing term limits should decrease the amount of pork, even if these are not binding in a given election. The latter is straightforward to understand - in the absence of re-election incentives, the politician does not have incentives to signal. Finally, the model finds that pork spending with signaling purposes occurs less towards the most ideologically dispersed group. This happens because in practice pork shifts the identity of the swing voter in the group receiving it towards the ideology of the incumbent. So by targeting voters more densely concentrated ideologically the incumbent is able to shift more votes with the same amount of expenditures. Intuitively, it means that more homogeneous groups are better at attracting benefits. ${ }^{3}$

These predictions are tested using a panel of state level data for the US from 1970 to 2000, including public expenditure and revenue, demographic characteristics, electoral data, and voters' preferences for the environment. To measure the latter an indicator was created, based on surveys, that mea-

\footnotetext{
${ }^{3}$ The idea that ideologically concentrated minorities can have disproportionate power in elections is also studied in McGann et al. (2002).
} 
sures the ideological dispersion of environmentally biased voters in each state. Pork barrel is measured by systematic deviations in environmental expenditures in election years, relative to the mean of all the other years of the mandate of the same politician. US state policy is a particularly relevant laboratory to test the predictions of the model, since environmental expenditures are decided at the state level with a large degree of independence and strong policy preferences of voters are known to politicians before elections. Additionally, the large amount of years available and detail of the data facilitate the identification strategy. The latter rests on the assumptions that conditional on state and year fixed effects and other covariates, the election year dummy is not correlated with any time varying characteristic in the error term.

The empirical results provide evidence in favor of environmental expenditures in the US being in fact subject to pre-electoral pork barrel with signaling purposes. Particularly, the analysis shows that in election years incumbents deviate systematically from their average expenditure levels by increasing environmental expenditures by around 4\%. Additionally, results show that in the case of democrat incumbents these distortions happen more in states where environmentally biased voters are less ideologically dispersed. These distortions remain visible when restricting the analysis to elections less likely to be decided on the basis of ideology and close elections.

The analysis thus provides an insight into the mechanism behind distortionary policies with electoral incentives, particularly regarding policies generating strong support from some groups of the population, and contributes to the literature on the political economy of environmental policy in countries with elected governments. These insights have implications for theoretical studies of electoral distortions, interest group power, and governance discussions around mechanisms to prevent inefficient behavior. These are discussed in the conclusion.

The remainder of the paper is organized as follows. The next section briefly revises some of the related literature. Section 3 describes and solves the theoretical model, and sets out the testable hypotheses it generates. Section 4 describes the empirical strategy and Section 5 its results. Finally, Section 6 concludes the paper and puts forward implications of the analysis. 


\section{Literature}

Large part of the existing theory on the use of pork distribution as an instrument to seek voter support focuses on models with full commitment by downsian politicians: following Downs (1957), candidates are purely officemotivated, and make binding promises as to the amount of pork spending they offer to voters. Some examples are Lizzeri and Persico (2001) and Persson and Tabellini (1999). However, politicians as citizens are likely to care not only about being in office but also about the policies performed, such that full commitment cannot be guaranteed. This idea is explored in citizen-candidate models (Osborne and Slivinski, 1996 and Besley and Coate, 1997), where politicians are citizens who decide to apply for office in order to implement their preferred policy. A model of pork spending where politicians have policy preferences is developed by Bouton et al. (2014), who use a retrospective probabilistic voting model to determine when politicians cater to a secondary issue, gun control, that a minority cares about, or a primary issue. However, a large body of research has found that prospective evaluations are important determinants of voting choices, in some cases more so than retrospective ones. ${ }^{4}$

Pre-electoral distortions are conciliated with forward-looking voters by political business cycle models, where incumbent politicians signal their competence by increasing expenditures or decreasing taxes, at the expense of the lately observed deficit. ${ }^{5}$ The main idea is that, because information is costly, rational forward looking voters infer incumbent's quality by the amount of expenditure they can provide, for a given level of taxes, and vote for the ones perceived as competent. However, these models imply voters do not observe some economic variable prior to elections, which is less likely to happen in developed democracies where more and better information is available. ${ }^{6}$ In established democracies distortions are more likely to arise from incomplete information regarding preferences of the incumbent. If these persist over time, current policy can be used as an indicator of future actions. This idea is used to evaluate how a politician may signal preference for expenditures that benefit the population instead of herself, by Drazen and Eslava (2010), with an empirical application evaluating the increase of highly visible expenditures in election years in Colombian municipalities. Redistribution

\footnotetext{
${ }^{4}$ See for example Lewis-Beck, 1990, Lockerbie, 1992, and Erikson et al. (2000).

${ }^{5}$ The seminal work by Nordhaus (1975) was later extended to include rational expectations by Rogoff and Sibert (1988) and Rogoff (1990).

${ }^{6}$ Brender and Drazen (2005) find that political budget cycles tend to disappear in established democracies, as voters become better at collecting and reporting relevant data.
} 
between issues that population groups value differently, however, may also arise for signaling purposes. Preferences for different groups or issues has been studied in two papers. Focusing on preferences for different groups, Morelli and Van Weelden (2013) develop a theoretical framework to study politicians' incentives to focus effort on issues where they can best signal their preferences to voters, and the effects of increased transparency on this allocation. Drazen and Eslava (2012), in turn, study programmatic targeting of different groups of population, finding that politicians target with expenditures larger groups and those with more swing voters, and do not often target to mobilize groups into going to vote. However, none of the previous papers offers an empirical analysis of the validity of the framework of signaling preferences for issues that given groups value but others do not. Finally, recent literature has focused on many aspects of the political economy of environmental policy. In particular, environmental expenditures in the US have been the subject of empirical analysis of political economy theories, mostly related to lobbying, but also to a lesser extent to electoral incentives. An example of the latter is List and Sturm (2006), who test how a secondary policy issue is affected by electoral incentives. In their model voters not only do not observe the politician's type, but also an economic shock happening prior to the election. In another study, Fredriksson et al. (2011) use regression discontinuity approaches to test whether elected politicians are mostly office or policy motivated. Both analyses address differences between terms where incumbents can be re-elected and those she cannot (she is a "lame duck"). Instead this paper focuses on election year behavior, giving rise to electoral cycles. At the same time this paper tests hypothesis from a different underlying behavior not included in previous studies.

\section{The Model}

The model in this section fits the citizen-candidate framework (Osborne and Slivinski, 1996, and Besley and Coate, 1997), in the sense of having politicians who, as citizens, have intrinsic policy preferences. Thus, they cannot credibly commit to a given platform. However, in this model, the politicians' preferences are not observed by the voters prior to elections. I will abstract from the entry decision, by assuming there is only one challenger, selected randomly from the pool of citizens, conditional on having a different ideology from the incumbent. The model also borrows from the Downsian 
framework (Downs, 1957), in the sense that candidates, in addition to having policy preferences, are office-motivated, which means that they obtain an additional payoff solely for being in power. Additionally, the model incorporates the possibility of using changes in current policies as a signaling tool for incumbents' unobserved characteristics, set out in the models of Rogoff and Sibert (1988) and Rogoff (1990). The distribution of the agents' policy and ideological preferences is the one in Persson and Tabellini (1999).

\subsection{Setup}

The economy is composed by a continuum of citizens, divided into three groups of equal size, $i=1,2,3$, that differ in two dimensions: their preferences regarding fiscal policies (how the budget is divided) and their ideology. There are two time periods, $t=1,2$, with a single election taking place at the end of period 1, between an incumbent politician $(I)$ and a randomly selected challenger $(C)$. The incumbent in each period decides on what will be called the fiscal policy: how to allocate a fixed budget, $T$, between expenditures targeted at one of three particular issues, $g_{i, t}$, and a bundle of national level expenditures, which benefit all the population equally, $G_{t}$. The targeted expenditures are expenditures on issues for which voters care in different ways - namely, voters who have a preference for certain issues derive utility from those expenditures, while the others do not. A good example is spending in environmental protection, for which some citizens with environmental concerns have strong preferences and so they value them, while others do not. ${ }^{7}$ In particular, I assume voters in each of the three groups derive utility from only one of the three expenditures: voters in group $i$ derive utility from $g_{i, t}$. Politicians, as citizens, also have policy preferences - i.e., they derive utility from one of the targeted expenditures. Policy preferences are not known to voters, but only the distribution of preferences of the population. Politicians also derive utility simply from being in office, from extracted rents or prestige.

The agents in the model also have ideological preferences, which are known and uncorrelated with their policy preferences, and include for example their position on issues like abortion or drug policy. The model further assumes the incumbent belongs to a party that is on one side of the ideological spectrum and the challenger to the one on the opposite. Theoretical results for downsian models with slightly policy-motivated politicians and some uncer-

\footnotetext{
${ }^{7}$ This is an assumption made for simplicity. In reality, one could argue that even those citizens that do not have environmental concerns will benefit from environmental action, through improved air quality for example.
} 
tainty on voters' behavior show that parties locate symmetrically around the median voter. ${ }^{8}$ Finally, ideological preferences include a general popularity shock: the incumbent may be more or less popular before the election, because of some personal factor. ${ }^{9}$ The realization of the popularity shock is not known to the incumbent prior to the election, such that when deciding on policy the incumbent is uncertain of the outcome of the election, conditional on her choices.

The timing of the model is the following: in period zero nature chooses the policy preferences and ideology of the incumbent, challenger and voters, and during the first period, the incumbent chooses the allocation of the budget, which voters observe. At the end of period one, the challenger is chosen from the population, the popularity shock is realized, and the citizens vote. In the second period the candidate who is elected, according to the majoritarian voting rule, chooses the policy to be implemented.

\subsubsection{The budget constraint}

In a given period $t$ the incumbent politician faces the following budget constraint:

$$
\sum_{i}^{3} g_{i, t}+G_{t}=T
$$

where $T$ is a fixed value, equal for each period, $G_{t}$ is continuous, with $0<G_{t}<T$, and expenditures targeted at each issue $g_{i, t}$ are for simplicity assumed to be of a discrete nature: $g_{i}=\{1,0\}$. They each have an equal cost, with the cost of spending on all adding to $T$, such that spending on one of them would take up one third of the budget. ${ }^{10}$ The incumbent's

fiscal policy can then be summarized as a vector $q_{t}^{I}=\left[\left\{g_{i, t}\right\}_{i=1,2,3}, G_{t}\right]$, where the superscript $I$ indicates that it is the incumbent's choice. As is standard in the pork barrel literature, $G_{t}$ is by assumption the efficient choice, which benefits all groups equally. ${ }^{11}$ However, $g_{i, t}$ can be targeted

\footnotetext{
${ }^{8}$ See, for example, Calvert (1985).

${ }^{9}$ Voters may be more inclined to vote for a politician if she is perceived as respectful or competent in the latest public appearances or news reports.

${ }^{10}$ The case with continuous choices would require additional assumptions on the shape of utility functions, but for given characteristics the main results would not change qualitatively.

${ }^{11}$ See, for example, Lizzeri and Persico (2001).
} 
to specific group(s), thereby increasing the probability of getting the votes of the particular group more sharply. So the incumbent faces a trade-off between efficiency and targetability.

\subsubsection{Voters}

Voters are divided into three groups, $i=1,2,3$, each with a continuum of citizens with unit mass, where preferences over fiscal policy are identical for all members of each group. The one-period utility, derived from fiscal policy, of a voter from group $i$ in time $t$ if policy $q_{t}^{I}$ is being performed can be written as:

$$
U_{i, t}\left(q_{t}^{I}\right)=\mu_{i} g_{i, t}+v\left(G_{t}\right), \quad g_{i}=\{1,0\}
$$

where $\mu_{i}$ is a markup measuring the increase in utility from having expenditures in the preferred issue made, $g_{i, t}$ is equal to 1 if these expenditures are made and 0 otherwise, and $v($.$) is monotonically increasing and concave.$ The fact that $\mu_{i}$ varies across groups accounts for the intensity of preferences, as some issues elicit stronger positions.

In addition to deriving utility from fiscal policy, voters have preferences over other aspects of political decision making ("ideological preferences"), which include individual ideologies and the general popularity of the incumbent. The ideological distribution used here is the one in Persson and Tabellini (1999), but adapted to the signaling structure of the present model. A voter $j$ in group $i$ has an ideological preference for the challenger, which can be positive or negative, given by $\left(\delta+\sigma^{j}\right)$. Here, $\delta$ is the general popularity of the challenger, ${ }^{12}$ due to some personal characteristic or charisma, and is a random variable with uniform distribution with expected value zero and density $z$. That is, $\delta \sim U\left[-\frac{1}{2 z}, \frac{1}{2 z}\right]$. The shock is realized at the end of the first period, before the election, so the incumbent decides on first period policies under uncertainty. In turn, $\sigma^{j}$ is the individual ideology of voter $j$ of group $i$, which is distributed according to a uniform distribution with expected value $\bar{\sigma}^{i}$ (group $i$ 's specific mean), and density $d^{i}$. That is, $\sigma^{j} \sim U\left[-\frac{1}{2 d^{i}}+\bar{\sigma}^{i}, \frac{1}{2 d^{i}}+\bar{\sigma}^{i}\right]$. The distributions are common knowledge, but only the agent $j$ observes her own parameter $\sigma^{j}$. As in Persson and Tabellini (1999), I assume $\bar{\sigma}^{1}<\bar{\sigma}^{2}<\bar{\sigma}^{3}$, and $\bar{\sigma}^{2}=0$. That is, group 2 is the one with more ideologically neutral, or swing, voters. Additionally, as they do, I assume group 2 is the one with the highest density $\left(d^{2}>d^{1}, d^{3}\right)$,

\footnotetext{
${ }^{12}$ The general popularity of the incumbent is the symmetrical opposite of the challenger's popularity.
} 
that $d^{1}>d^{3}$ and that $\bar{\sigma}^{1} d^{1}+\bar{\sigma}^{3} d^{3}=0$. The assumptions on the ordering of densities are made without loss of generality: the results do not change qualitatively for any ordering. ${ }^{13}$ The last assumption, along with $\bar{\sigma}^{2}=0$, is made for simplicity, and means that the number of voters to the right and the left of the ideologically neutral ones is the same. If this assumption was to be relaxed, the ordering of densities would have an effect, as one of the politicians would have an ideological advantage (which would be larger the higher the density of the group with the same ideology). However, this analysis is beyond the scope of the paper. The ideological distribution of voters can be summarized in Figure 1.

Figure 1: Ideological distribution of voters

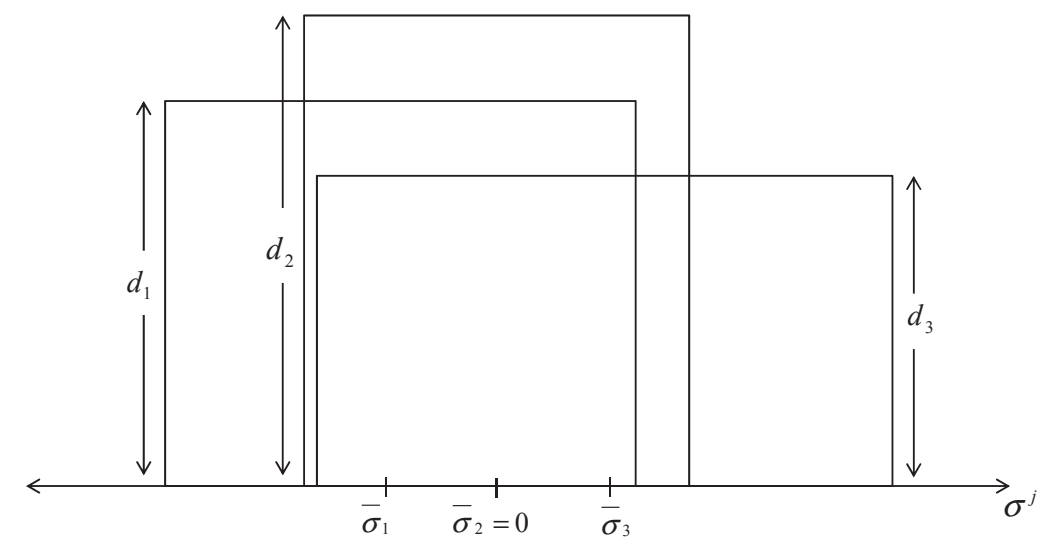

Closer to Incumbent's Ideology Closer to Challenger's Ideology

The figure shows that all the groups have ideologically neutral voters. However, according to the density distribution, group 2 has the most, followed by 1 , and finally, group 3 has the least swing voters. The main idea is that, if $\delta=0$, an ideologically neutral voter will cast her vote solely on basis of her fiscal utility (i.e., vote for the incumbent if $E\left[U_{i}\left(q_{t+1}^{I}\right)\right] \geq$ $\left.E\left[U_{i}\left(q_{t+1}^{C}\right)\right]\right)$.

\footnotetext{
${ }^{13}$ As will be clear from the equilibrium conditions, changing the ordering of densities will only affect the type of incumbent that plays a given strategy, but not the qualitative results.
} 


\subsubsection{The Politicians}

The politician's utility in period $t$ is analogous to that of a citizen, but includes the payoff from being in office, $\gamma$. For an incumbent with a preference for issue $k, k=1,2,3:^{14}$

$$
w_{k, t}^{I}\left(q_{t}^{I}\right)=U_{k, t}^{I}\left(q_{t}^{I}\right)+\gamma=\mu_{k} g_{k, t}+v\left(G_{t}\right)+\gamma, \quad g_{k, t}=\{1,0\}
$$

where $w_{k, t}^{I}\left(q_{t}^{I}\right)$ is the total utility of an incumbent in period $t$, and $U_{k, t}^{I}\left(q_{t}^{I}\right)$ stands again for the utility derived solely from fiscal policy $q_{t}^{I}$. The incumbent chooses current policy in order to maximize her two-period utility, $W_{k}^{I}$, which depends on the utility in equation (3) and the probability of being re-elected, $\pi$, which is defined later:

$$
W_{k}^{I}=U_{k, t}^{I}\left(q_{t}^{I}\right)+\gamma+\beta\left[\pi\left(U_{k, t}^{I}\left(q_{t}^{I}\right)+\gamma\right)+(1-\pi)\left(E\left[U\left(q_{t+1}^{C}\right)\right]\right)\right]
$$

where $\beta$ is the discount factor, and the superscripts $I$ and $C$ indicate choices of the incumbent and the challenger, respectively. Ideologically, the incumbent is located to the left of $\bar{\sigma}^{2}$ and the challenger to the right. They are further located symmetrically around the $\bar{\sigma}^{2}$ such that this is the location of the ideologically neutral voter. ${ }^{15}$

\subsubsection{Voting Behavior and Beliefs}

Voters make their decision according to their policy and ideological preferences. They are forward-looking and wish to maximize their second period expected utility. So, in choosing the best candidate, they compute their expected utility in $t+1$ under each of them, and vote for the one that gives them the highest, conditional on the ideological bias not offsetting this. Voter $j$ in group $i$ will, therefore, vote for the incumbent if:

$$
E\left[U_{i, t+1}\left(q_{t+1}^{I}\right)\right]>E\left[U_{i, t+1}\left(q_{t+1}^{C}\right)\right]+\left(\delta+\sigma^{j}\right)
$$

Since policy is multi-dimensional, the notion of probabilistic voting will be used to find an equilibrium. The vote share of the incumbent in group $i$, $S^{I, i}$, is thus given by:

\footnotetext{
${ }^{14}$ Throughout the analysis $k$ will be used to indicate the politician's type and $i$ the citizens' type, where $k, i=1,2,3$. The type always refers to the preference for one of the three particularistic expenditures.

${ }^{15}$ The same assumption is made in Persson and Tabellini (1999).
} 


$$
S^{I, i}=d^{i}\left[E\left[U_{i, t+1}\left(q^{I}\right)\right]-E\left[U_{i, t+1}\left(q^{C}\right)\right]-\delta-\bar{\sigma}^{i}\right]+\frac{1}{2}
$$

The probability of winning the election differs depending on the electoral rule in place. Since the empirical analysis is performed for US gubernatorial elections, I focus on a majoritarian system with a single electoral district. ${ }^{16}$ Under a single-district system, a politician in each state wins the election if she obtains more than $\frac{1}{2}$ of the total votes of the population in that state. Thus the incumbent's probability of winning in given by:

$$
\pi_{q^{I}}^{I}=\operatorname{Pr}\left[\frac{\sum_{i=1}^{3} S^{I, i}}{3} \geq \frac{1}{2}\right]
$$

By equation (7), the assumption on the distribution of $\delta$, and the assumptions on the distribution of voters' preferences, ${ }^{17}$ this probability is given by:

$$
\pi_{q^{I}}^{I}=\frac{z}{\sum_{i=1}^{3} d^{i}}\left[\sum_{i=1}^{3} d^{i} \varepsilon^{i}\right]+\frac{1}{2}
$$

where $\varepsilon^{i}=E\left[U_{i, t+1}\left(q^{I}\right)\right]-E\left[U_{i, t+1}\left(q^{C}\right)\right]$

Voters have prior probability $\lambda_{i}^{P}$ that a politician $P=I, C$ is of type $i$, for each $i=1,2,3$. After observing first period policies, voters in each group update their beliefs on the incumbent's type through Bayesian updating, while keeping their prior on the challenger. Hence, the incumbent has a scope to use current policy to change voter's beliefs regarding her preferences, that is, to signal a type, which might not be the true one. If the politician's signaling changes the voters' prior beliefs, we say it was effective.

\subsection{Full Information Benchmark}

The model is solved by backwards induction. Since there are no more elections after the last period, in $t+1$ the politician of type $k=1,2,3$ in power

\footnotetext{
${ }^{16}$ The analysis is easily extendable to a multiple district framework, which national level elections would fit. The results of this case are available upon request, and show that pork barrel with signaling purposes occurs even more frequently under a multiple district electoral rule.

${ }^{17}$ In particular, that $\bar{\sigma}^{2}=0$ and $\bar{\sigma}^{1} d^{1}+\bar{\sigma}^{3} d^{3}=0$
} 
simply chooses the policy that maximizes her utility:

$$
\begin{array}{ll}
\max _{g_{i, t+1}} & \mu_{k} g_{k, t+1}+v\left(G_{t+1}\right)+\gamma \\
\text { s.t. } & \sum_{i}^{3} g_{i, t+1}+G_{t+1}=T
\end{array}
$$

for $i=1,2,3$. Thus the politician will never decide to spend on other issues apart from her preferred one. Assuming $v(T)-v\left(T-g_{k, t+1}\right)<$ $\left.\mu_{k} g_{k, t+1}\right), \forall k$, the politician will spend on $g_{k, t+1}$, instead of using all the budget for the national level good. Hence, $q_{t+1}^{P}=\left\{G_{t+1}^{*}, g_{k, t+1}\right\}$, where $G_{t+1}^{*}=T-g_{k, t+1}$.

With full information on the voters' side the preferences of the politician are known, so there is no scope for signaling. Thus also in the first period the incumbent chooses the fiscal policy that maximizes her period utility, $q_{t}^{I}=$ $\left\{G_{t}^{*}, g_{k, t}\right\}$, where again $G_{t}^{*}=T-g_{k, t}$ and $k=\{1,2,3\}$ is the incumbent's preferred issue. The only uncertainty is on the incumbent's side, regarding the realization of the popularity shock $\delta$.

In this setting there are two categories of equilibria, depending on whether the politicians are of the same type or of different types. If the incumbent and the challenger have a preference for the same issue, then the probability of winning is equal to $\frac{1}{2}$, independent of group densities or the politicians' popularity. To see this note that $U_{i, t+1}\left(q_{t+1}^{I}\right)=U_{i, t+1}\left(q_{t+1}^{C}\right), \forall i=\{1,2,3\}$, that is, $\varepsilon_{i}=0$, so the incumbent's vote share in each of the three groups simplifies to $S^{I, i}=d^{i}\left[-\delta-\bar{\sigma}^{i}\right]+\frac{1}{2}$.

This means that $\pi_{q^{I}}^{I}=\frac{z}{\sum_{i=1}^{3} d^{i}}\left[\sum_{i=1}^{3} d^{i} \varepsilon^{i}\right]+\frac{1}{2}=\frac{1}{2}$.

If the politicians are of different types, with the incumbent of type $k$ and the challenger $j$, the utility differential of having the incumbent in power for voters in group $k$ is positive and given by $\varepsilon^{k}=U_{k, t+1}\left(q_{t+1}^{I}\right)=U_{k, t+1}\left(q_{t+1}^{C}\right)>$ 0 . Similarly, $\varepsilon^{j}<0$ and for the third group it is once again zero. The incumbent's winning probability is thus given by $\pi_{q^{I}}^{I}=\frac{z}{\sum_{i=1}^{3} d^{i}}\left[d^{k} \varepsilon^{k}+d^{j} \varepsilon^{j}\right]+$ $\frac{1}{2}=\frac{1}{2}$. Whether the expression in brackets is positive or negative depends on the densities of the two groups. Since $d^{2}>d^{1}>d^{3}$ a politician of type two will win over the other two types, and type one will win over type three. With full information the policy performed is always $q_{t}^{P}=\left\{G_{t}^{*}, g_{k, t}\right\}$, where $k$ stands for the politician's preference. 


\subsection{Asymmetric Information}

\subsubsection{Equilibrium Definition}

In the asymmetric information case, the equilibrium concept used will be that of a Perfect Bayesian Equilibrium (PBE).

\section{Definition 1 Equilibrium}

A Perfect Bayesian Equilibrium in this setting satisfies the following conditions:

(a) In the first period, the incumbent decides on the fiscal policy $q_{t}^{I}$ that maximizes her two period utility given by (4), subject to the belief system given by the priors and bayesian updating, her expected popularity, and the optimal strategies of voters;

(b) At the voting stage, voters in each group $i$ maximize their expected utility, subject to the belief system and the incumbent's first period decisions, and therefore vote for the incumbent if $E\left[U_{i}\left(q_{t+1}^{I}\right)\right]>E\left[U_{i}\left(q_{t+1}^{C}\right)\right]+\left(\delta+\sigma^{j}\right)$;

(c) Beliefs are consistent on the equilibrium path.

For simplicity, I restrict the analysis to $\mathrm{PBE}$ in pure strategies. With the distributional assumptions made, three particular cases arise, depending on which issue the incumbent has a preference for:

1. The incumbent has a preference for the issue favored by the most ideologically dispersed group (group 3)

2. The incumbent has a preference for the issue favored by the group with the most swing voters (group 2), that is, with higher density around the ideological mean

3. The incumbent has a preference for the group with intermediate ideological density (group 1)

The incentives for the incumbent to choose different policies vary between the cases. Due to the discrete nature of the expenditures targeted at each of the three issues, the incumbent's actions are also of a discrete nature: she can spend on all, three, one, or none of the issues. At this point it is convenient to define the pork barrel strategy.

\section{Definition 2 Pork Barrel}

Performing Pork Barrel in the current setting consists of spending, for reelection purposes, on more issues than what maximizes the politician's period utility. 
More specifically, as set out in Section 3.2, the politician's period utility is maximized by $q_{t}^{P}=\left\{G_{t}^{*}, g_{k, t}\right\}$. So the incumbent's non pork barrel $(\overline{P B})$ strategy in period $t$ is defined as $q_{t}^{\overline{P B}}=\left\{G_{t}^{*}, g_{k, t}\right\}$, where $G_{t}^{*}=T-g_{k, t}$ and the superscript $I$ was suppressed since only the incumbent chooses policy in period $t$. The incumbent's pork barrel $(P B)$ strategy is in turn given by $q_{t}^{P B}=\left\{G_{t}^{P B}, g_{k, t}, g_{i, t}\right\}, \forall i \neq k$, where $G_{t}^{P B}=T-g_{i, t}-g_{k, t}, i \neq k, i, k=$ $\{1,2,3\}$. Thus, we say that an incumbent is performing pork barrel if she spends on her favorite issue $k$ and one of the other two, instead of maximizing her period utility. When spending on two issues instead of one, the politician is signaling that she might have a preference for any of these two issues.

It is straightforward to see that a politician never chooses to spend on two issues that she does not have a preference for. I further assume she never spends on all three issues, thus choosing $G_{t}=0$, nor on none of the issues, thus choosing $G_{t}=T$ - that is, $0<G_{t}<T$. Both these strategies would not signal any type, but the former would give a lower utility than the latter as long as $\mu g_{k, t}<v\left(G_{t}=T\right)$. The latter is also always inferior to the PB strategy as long as $v\left(G_{t}=T\right)-v\left(G_{t}^{*}\right)<\mu g_{k, t}$. So as long as $v\left(G_{t}\right)$ is sufficiently concave the politician's optimal choice is between $q_{t}^{P B}$ and $q_{t}^{\overline{P B}}$.

\subsubsection{Political Economic Equilibrium}

When deciding between the two policies, $q_{t}^{P B}$ and $q_{t}^{\overline{P B}}$, the incumbent of type $k=\{1,2,3\}$ compares her expected utility under each, that is $E\left[W U^{I}\left(q_{t}^{P B}\right)\right]>E\left[W U^{I}\left(q_{t}^{\overline{P B}}\right)\right]$ which substituting in the previous equations is:

$$
v\left(G_{t}^{P B}\right)-v\left(G_{t}^{*}\right)+\beta\left[\left(\pi_{q_{t}^{P B}}^{I}-\pi_{q_{t}^{I B}}^{I}\right)\left(\left[1-\lambda^{k}\right] \mu_{k} g_{k, t+1}+\gamma\right)\right]>0
$$

Here $v\left(G_{t}^{P B}\right)-v\left(G_{t}^{*}\right)$ is the loss in utility in period $t$ from performing the pork strategy, and the expression in square brackets is the difference in the expected utility in $t+1$, relative to the non pork strategy. $\pi_{q_{t}^{P B}}^{I}-\pi_{q_{t}^{P B}}^{I}$ is the difference in re-election probability between performing and not performing the pork barrel strategy, and $\left[1-\lambda^{k}\right] \mu_{k} g_{k, t+1}+\gamma$ the gain in utility from being in office in $t+1$ relative to not being in office. By assumption $v\left(G_{t}^{P B}\right)-v\left(G_{t}^{*}\right)<0$. Whether or not there is an equilibrium where the politician performs pork thus depends on whether $\pi_{q_{t}^{P B}}^{I}-\pi_{q_{t}^{P B}}^{I}$ can be positive. 
The probability of re-election is affected by the incumbent's actions if they alter the voters' beliefs. The incumbent may target other issues apart from her favorite in order to affect the voters' expected utility differential, $\varepsilon_{t+1}^{i}, i=\{1,2,3\}$. In particular, if she signals a type other than her own $(-k)$ and this signaling is effective, $\varepsilon_{t+1}^{-k}$ increases. This is because then voters attribute a higher probability to the incumbent being of type $-k$ than if she had not signaled.

If she performs $q_{t}^{\overline{P B}}$ her type is revealed. This is because $\operatorname{Pr}\left(q_{t}^{\overline{P B}} \mid I \neq k\right)=0$, that is, the incumbent will never spend only on $g_{k, t+1}$ if she is of another type. So voters update their beliefs that the incumbent is of type $k$ according to:

$$
\operatorname{Pr}\left(I=k \mid q_{t}^{I, \overline{P B}}\right)=1
$$

which means that for voters in group $k$ the expected utility differential becomes positive, that is, $\varepsilon^{k}=\left(1-\lambda_{k}\right) \mu_{k} g_{k, t+1}$, while the opposite is true for the other two groups, where $\varepsilon^{-k}=-\lambda_{-k} \mu_{-k} g_{-k, t+1}$. The incumbent's probability of re-election is therefore given by the following expression.

$$
\pi_{q_{t}^{I, \overline{P B}}}^{I}=\frac{z}{\sum_{i=1}^{3} d^{i}} g_{t+1}\left(d^{k} \mu_{k}\left[\left(1-\lambda_{k}\right)\right]+\sum^{2} d^{-k} \mu_{-k}\left[-\lambda_{-k}\right]\right)+\frac{1}{2}
$$

where $g_{i, t+1}=g_{t+1}, \forall i=\{1,2,3\}$.

Alternatively, the incumbent may choose $q_{t}^{P B}=\left\{G_{t}^{P B}, g_{k, t}, g_{i, t}\right\}, \forall i \neq k$. In this case, she will spend on her favorite issue, $k$, and in one of the other two $i \neq k$. In choosing which of the other issues to target she compares the gain in the probability of winning in each of the other two groups. This is because when voters see that the incumbent spent on their favorite issue they will update their belief that the politician is of their type. However, relative to the $\overline{P B}$ strategy, the incumbent loses votes in her own group, as voters here no longer update the probability that she is of their type to 1. She will then perform the strategy if the gains in terms of votes in the targeted group outweigh the losses of votes in her own group plus the utility loss in the period before the election. The following proposition describes the main conclusion.

Proposition 1 Under certain thresholds describing the ordering of densities and intensity of preferences, given by equation (A.4), a political economy equilibrium exists where the incumbent performs the strategy $q_{t}^{P B}$. In this 
equilibrium, the incumbent uses pork barrel to signal effectively, thereby increasing her re-election probability.

Proof See Appendix A.

Whether this equilibrium exists depends on the ordering of densities and the intensity of preferences given by $\mu_{i}$. When the politician has a preference for the preferred issue of the group with the highest density, that is, $k=2$, for pork barrel to be effective $\mu_{1}-\mu_{2}$ or $\mu_{3}-\mu_{2}$ has to be large enough to compensate the fact that $d_{1}, d_{3}<d_{2}$. So, for given preference intensities, an incumbent is more likely to target highly densely concentrated groups. This means in particular that the group with the most dispersed ideology, group 3 , is less likely to be targeted, as for it to be targeted $\mu_{3}$ would need to be very high. If this does not happen when a politician has a preference for a more heterogeneous group signaling is not effective and so the incumbent does not perform the pork barrel strategy.

In practice, if it is effective in terms of altering the voters' beliefs about the preferences of the incumbent, delivering pork corresponds to a shift in the position of a given group in Figure 1 towards the left. This implies that it is always better for the incumbent to target groups with higher densities. An incumbent will only target a group with a lower density than the one she has a preference for if the valuation of the preferred issue by that group is strong enough. Thus, the pork barrel strategy might arise in equilibrium for signaling purposes, but is less likely to occur towards ideologically heterogeneous groups. Intuitively, this means that ideologically homogeneous groups are better at attracting pork, as they are more easily swayed.

From equation (10), whenever $\pi_{q_{t}^{P B}}^{I}-\pi_{q_{t}^{I B}}^{I}>0$, that is, whenever equation (A.5) is satisfied, the incumbent has an incentive to perform the pork barrel strategy. Her incentive to do so is larger the larger $\beta$ is - that is, the more future oriented the politician is - the larger $\mu_{k}$ is - that is, the more the incumbent values her preferred issue - the lower the valuation of $G_{t}$ and the prior on the challenger's type $\lambda_{k}$ are, and the higher the payoff of being in office, $\gamma$, is. Intuitively, an incumbent that is future oriented or has a high payoff of being in office is willing to give up more utility in the present in exchange for re-election.

These results can be summarized in the following proposition.

Proposition 2 The conditions under which pork barrel arises as an equilibrium strategy for signaling purposes are given by equations (10) and (A.4). 
This equilibrium is characterized by a high density and intensity of preferences of the targeted group, a low discount factor, a high valuation of the targeted expenditures relative to the public good, and a high payoff for being in office.

\subsubsection{Empirical Implications}

The model derives conditions under which pork barrel may arise as an equilibrium strategy for an incumbent, thus putting forward testable implications. The first is that in majoritarian systems before elections particularistic expenditures should be systematically higher than those made during the rest of a politician's mandate. When politicians behave differently in election years they are deviating from the policy that maximizes their fiscal utility $u_{k, t}^{I}\left(q_{t}^{I}\right)$.

The second and third refer to re-election incentives. Particularly, we should not see election year increases in particularistic expenditures if voters with strong preferences for them are more ideologically dispersed than the average population. If these distortions are in fact generated by the signaling motive then politicians will choose to perform them towards groups that are more densely concentrated ideologically and are therefore easier to sway. Additionally, these distortions should not take place when a politician cannot be re-elected - when she is a "lame duck" - and they should be smaller when she is subject to term limits, even when they are not binding. The intuition for the former is that, if an incumbent cannot run for re-election, she does not have an incentive to signal her preferences through current policy. In reality however a politician might still have an incentive to perform pork, if she expects to be elected to another position or cares about her party's future victory. Although pork barrel might still take place, it is expected it does to a lesser extent for "lame duck politicians". The latter is a measure of the time horizon of the politician, and should therefore approximate her discount factor: if an incumbent is not subject to term limits she has a much higher potential future payoff, which in our simplified framework means she has a smaller discount factor. Thus she should have a higher incentive to perform pork. 


\section{Empirical Strategy}

The model is tested for the case of U.S. state level policy, namely for environmental expenditures. Gubernatorial elections in the U.S. take place under a majoritarian single-district system. This is a particularly suitable laboratory to test the signaling motive for the pork barrel hypothesis for several reasons. The first is that U.S. governors have substantial control over several policy areas, including environmental policy (List and Sturm (2006)). This provides state governments with significant discretion over their expenditures. The second is that the environment triggers strong opinions by the electorate, which makes it a natural candidate to be used as pork with electoral purposes. ${ }^{18}$ The third is that in the U.S. a large number of surveys are conducted before elections, such that incumbents are likely to be well informed of the preferences of the electorate, particularly regarding salient issues. Finally, the large number of years available and the detail of the data allows for a rich analysis of incentives, while facilitating the identification strategy.

\subsection{Variable Definition}

A first key empirical question is what constitutes pork barrel spending. Here pork barrel is defined as the environmental expenditures occurring in election years in excess of what the politician's choice would have been in the absence of electoral incentives. Accordingly, it is calculated as the deviation in environmental spending in election years with respect to the average expenditure for each incumbent politician. This measures whether election year decisions differ from what is optimal for the same politician in every other year. ${ }^{19}$

In order to measure voters' environmental preferences and ideological dispersion I use responses to surveys representative at the state level. ${ }^{20}$ For each respondent I measure the degree of environmental preference and the ideological inclination. The first uses a scale from responses on questions about the importance of the environment and government's action regarding the environment, $e n v_{i}$, and the second uses the answer to the question of whether the respondent is a conservative, moderate, liberal, or does not

\footnotetext{
${ }^{18}$ The idea that the environment is a pivotal issue in sub-national elections is defended by Lake (1983) and Udall (1987).

${ }^{19}$ Results with alternative measures are discussed at the end of Section 5 and Appendix C.

${ }^{20}$ The surveys are described in Section 4.4. and Appendix B.
} 
think in those terms. The ideological inclination is used to create an indicator of ideological dispersion at the state level, totdisp $_{i}$, by calculating the standard deviation of this measure in each state. The degree of environmental preference, in turn, is used to classify respondents into environmentally biased or not, simply by generating a dummy equal to 1 if $e^{n} v_{i}$ is higher than the mean of the population and 0 otherwise, and calculating the ideological dispersion in each state only if the dummy is 1 , envdisp $p_{i}$. These are combined to calculate the dispersion of environmental voters' ideology relative to the total dispersion in state $i$ as $d i s p_{i}=\frac{\text { envdisp }_{i}}{\text { totdisp }_{i}}$. I experiment with different cutoffs for the dummy variable, but since the results do not vary I use only this indicator.

\subsection{Econometric Model}

The analysis aims at assessing the existence of election-year distortions in environmental spending across states, and the factors contributing to them. The basic empirical model is given by

$$
\text { deviation }_{i p t}=\alpha_{1}+\text { Selyear }_{i t}+\alpha_{2} X_{i t}+\rho_{t}+\eta_{i}+\epsilon_{i t}
$$

where deviation $_{\text {ipt }}$ is the yearly relative deviation in terms of environmental expenditures relative to a politician's $(p)$ mean in state $i$ in year $t$. It is calculated as

$$
\text { deviation }_{\text {ipt }}=\frac{\text { envexp }_{i p t}-\text { average }_{i p}}{\text { average }_{i p}}
$$

where average $_{i p}$ is the average environmental expenditure over the time in office for a given politician. As in List and Sturm (2006), total environmental expenditures are the sum of expenditures in three categories: forests and parks, fish and games, and others. They argue they can be pulled together as all three record very similar types of spending and are used as substitutes. Expenditures are deflated to 1982-1984 dollars and expressed in per capita terms. The main variable of interest is elyear ${ }_{i t}$, a dummy variable equal to 1 if year $t$ is an election year in state $i$ and 0 otherwise. $X_{i t}$ is a vector of economic and demographic variables affecting fiscal choices for each state, $\rho_{t}$ are time dummies, $\eta_{i}$ is a state fixed effect, and $\epsilon_{i t}$ is the error term. The fixed effect is included to control for unobserved heterogeneity. Alternatively, the variable measuring how environmentally biased a population of a given state is, envbias ${ }_{i}$, is included. Given that this variable does not vary with time fixed effects are not included when the variable is. The main coefficient of interest is therefore $\delta$, that measures systematic changes 
in the dependent variable occurring in election years. If pork barrel takes place for environmental expenditures this coefficient should be positive and significant.

The control variables included in $X_{i t}$ aim at capturing a given state's resources and needs. The variables $17_{i t}$ and $65_{i t}$, respectively the percentage of people between 5 and 17 and over 65 years old in state $i$ at time $t$, measure population needs, taxerevenue ${ }_{i t}$, the real per capita taxes in state $i$ at time $t$, and income $_{i t}$, the real per capita state income at time $t$, provide a measure of the state's resources, and popit, the state population in millions, is included to account for economies of scale or congestion effects in the provision of public goods. Finally, the average of environmental expenditures for each politician, average $e_{i p}$, is included and a negative coefficient is expected, as the higher the expenditures are during the mandate the more difficult it is to increase them.

The main identification strategy relies on the fact that, conditioning on state fixed effects, time fixed effects, and other covariates, the election year dummy is not correlated with any time varying characteristic included in the error term.

To the basic model additional variables are then added, in turn, to test further implications. The prediction that pork occurs less towards ideologically dispersed groups is tested by including the interaction of the dispersion index $\operatorname{disp}_{i}$ with the election year dummy, while also including the index separately. For this variable a negative coefficient is expected: environmental expenditure deviations in election years should be lower in states where citizens with environmental preferences are dispersed ideologically when compared to those less dispersed. To test whether politicians who cannot be re-elected have different incentives lame $_{i t}$ in included, a dummy equal to 1 if the incumbent is a "lame duck" (i.e., she is not up for re-election) and 0 otherwise. The interaction of this dummy with the election year dummy thus measures election year incentives for "lame ducks" as compared to incumbents that can be elected. Thus a negative sign is expected. As a proxy for the politician's time horizon, a dummy variable equal to 1 if state $i$ has term limit legislation at time $t$ and 0 otherwise, limit $_{i t}$, is included, and an interaction of this with the election year dummy. The coefficient of the interaction term is expected to be negative, indicating that if the time horizon of a politician is smaller, incentives to perform pork decrease.

Lastly, to test the robustness of the model a number of criteria are used to restrict the sample. If signaling is in fact the motivation for pork policies, then we should observe these more amongst democrats, for whom the signaling is more effective, and more in elections that are less likely to be decided 
in terms of ideology alone. Thus the sample is restricted respectively to include only democrat governors, and elections where the average democratic vote share was neither too large nor too small. A measure of political competition is used to test if results are maintained when restricting attention to close elections, as we would expect pork barrel to take place more often when political competition increases.

\subsection{Data}

The database used includes information for the 48 continental states in the US between 1970 and 2000, making a total of 1488 observations.

Data on environmental expenditures as well as all political and demographic variables used in the analysis come from List and Sturm (2006). The political variables are in turn updated versions of the data used in Besley and Case (1995), with the exception of the average democratic vote share and the index of political competition from Ansolabehere and Snyder Jr (2002). The demographic variables were collected from the Census of State Governments. Data on state environmental preferences and ideology was collected from five surveys, conducted between 1983 and 2007. These surveys were conducted by CBS with the New York Times, and ABC News with Stanford University and Time Magazine, and are available from the Inter-university Consortium for Political and Social Research (ICPSR). They include questions that measure environmental inclination, such as a classification of the importance of the environment, as well as ideological preferences.

According to List and Sturm (2006), environmental inclination is persistent over time in US states (namely between 1987 and 2000). Thus I pull together the information on the five surveys, which allows me to have 4824 individual observations, from which the state ideological dispersion and degree of environmental inclination are calculated. The resulting measure of environmental preference is correlated, although varying considerably less, with that of List and Sturm (2006), consisting of the percentage of state population enrolled as a member of the largest environmental organizations.

Table 1 presents the summary statistics for the data. The first six rows represent the measures of environmental expenditures used, specifically: total spending and its three disaggregated components per capita, deviation from politician average, and average environmental expenditures while in power by politician. Environmental expenditures vary largely across states and time between a minimum of 6119 and a maximum of 168297 dollars per capita. The relative deviation in environmental expenditures varies from - 
Table 1: Summary statistics

\begin{tabular}{lccccc}
\hline \hline \multicolumn{1}{c}{ Variable } & Mean & Std. Dev. & Min & Max & Obs \\
\hline Environmental Expenditures & 27.058 & 16.983 & 6.119 & 168.297 & 1488 \\
Fish \& Game & 6.836 & 6.697 & 0.515 & 52.086 & 1488 \\
Forests & 11.522 & 6.712 & 0.560 & 58.666 & 1488 \\
Other Environmental & 8.701 & 9.026 & 0.164 & 118.244 & 1488 \\
Deviation & 0 & 0.167 & -0.771 & 0.879 & 1488 \\
Governor Average Environmental & 27.058 & 16.145 & 7.741 & 131.845 & 1488 \\
\hline Taxes in State & 0.817 & 0.219 & 0.316 & 1.731 & 1488 \\
Personal Income & 12.914 & 2.537 & 6.745 & 24.093 & 1488 \\
Total Expenditures & 1.454 & 0.393 & 0.669 & 2.921 & 1488 \\
\hline State Population in millions & 4.956 & 5.191 & 0.334 & 34.002 & 1488 \\
Percentage between 5-17 & 0.209 & 0.029 & 0.071 & 0.304 & 1488 \\
Percentage over 65 & 0.118 & 0.02 & 0.04 & 0.188 & 1488 \\
\hline Election & 0.277 & 0.448 & 0 & 1 & 1488 \\
Lame Duck & 0.261 & 0.439 & 0 & 1 & 1488 \\
Term Limits & 0.606 & 0.489 & 0 & 1 & 1488 \\
Democrat & 0.558 & 0.497 & 0 & 1 & 1472 \\
Democratic vote & 0.526 & 0.089 & 0.218 & 0.946 & 1488 \\
Political competition & -0.069 & 0.062 & -0.446 & 0 & 1488 \\
\hline Environmental Preference & 13.044 & 4.632 & 3.609 & 31.888 & 1488 \\
Dispersion Index & 0.92 & 0.214 & 0.203 & 1.415 & 1488 \\
Dispersion Environmentalists & 0.84 & 0.272 & 0.4 & 1.927 & 1488 \\
State Ideological Dispersion & 1.68 & 0.748 & 0.773 & 5.581 & 1488 \\
\hline
\end{tabular}

Sources: List and Sturm (2006) and ICPSR.

Monetary variables expressed in real per capita dollars.

0.771 to 0.879 . Figure 2 shows a scatterplot of total deviations across states by year in circles, along with a sum of elections across states by year in triangles. The following three rows include the economic control variables, followed by the three demographic control variables. The dummy for term limits includes states with a one, two or three period term limit, and the legislation in several states changed during the sample period, with 13 states having implemented term limits during the period covered by the sample, two of which abolished them subsequently. ${ }^{21}$ Finally the last four rows are the variables constructed from the survey data. Appendix B describes the surveys in more detail and presents maps with the resulting measure of environmental bias and the ideological dispersion index.

\footnotetext{
${ }^{21} \mathrm{~A}$ description of the term legislation in each state, as well as detailed sources, can be found in List and Sturm (2006).
} 
Figure 2: Deviations and Election Years

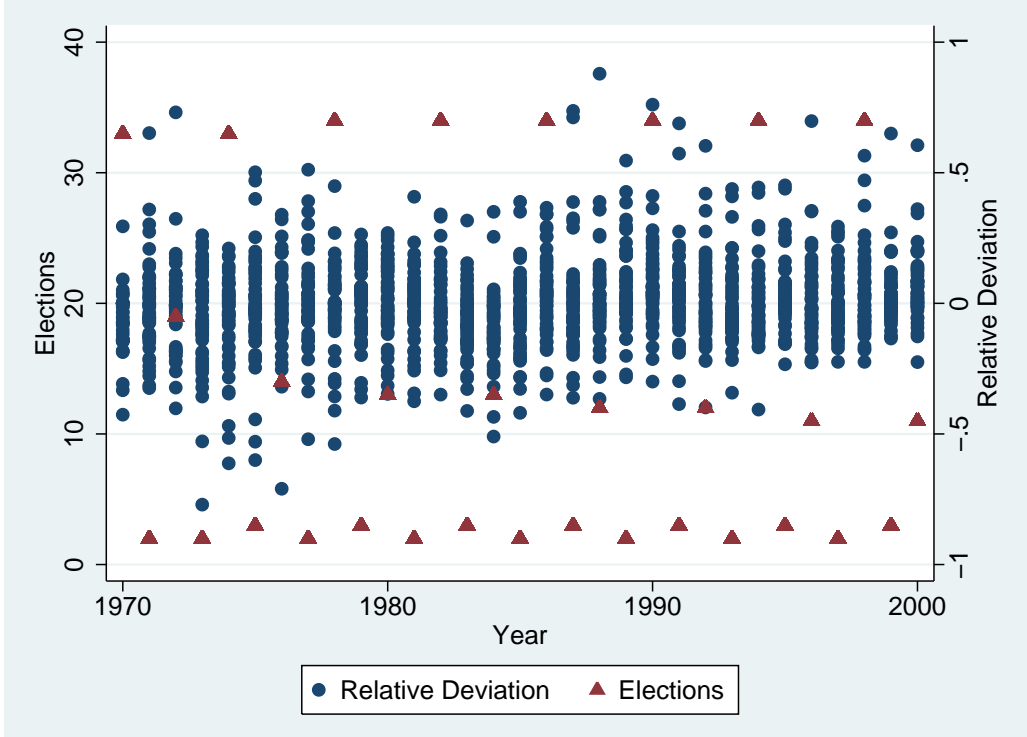

\section{$5 \quad$ Results}

The results from the basic model in equation (13) are presented in Table 2. All estimations in this and subsequent tables include time fixed effects and robust standard errors are clustered at the state level. Tax revenues, income, and population are logarithmized in all estimations in which they are included. The main estimations were performed using Fixed Effects (FE), ${ }^{22}$ with the results estimated by Ordinary Least Squares (OLS) included in the first column for comparison.

Column (1) presents the OLS coefficient estimation for the model with only the election year dummy and time effects, and column (2) presents the same regression estimated through $\mathrm{FE}$. The coefficient of the election year is significant in both estimations, but becomes larger after introducing state fixed effects. Column (3) presents the full estimation, including demographic and economic control variables. The coefficient of the election year dummy is positive and statistically significant at a $1 \%$ significance level. In particular, election years see environmental expenditures increase relative to an incumbent's mean by $4 \%$ on average (column 4 ). This represents an increase in over one dollar per capita in election years.

\footnotetext{
${ }^{22}$ A Hausman specification test gives preference to FE over Random Effects (RE).
} 
Table 2: Basic Model Results

\begin{tabular}{|c|c|c|c|c|c|}
\hline VARIABLES & $\begin{array}{l}\text { (1) } \\
\text { OLS }\end{array}$ & $\begin{array}{l}(2) \\
\mathrm{FE}\end{array}$ & $\begin{array}{l}(3) \\
\mathrm{FE}\end{array}$ & $\begin{array}{l}(4) \\
\mathrm{FE}\end{array}$ & $\begin{array}{c}(5) \\
\text { GMM }\end{array}$ \\
\hline deviation $_{i t-1}$ & & & & $\begin{array}{c}0.419 * * * \\
(0.0466)\end{array}$ & $\begin{array}{c}0.528 * * * \\
(0.0486)\end{array}$ \\
\hline elyear $_{i t}$ & $\begin{array}{c}0.0396^{* * *} \\
(0.00796)\end{array}$ & $\begin{array}{c}0.0408^{* * *} \\
(0.00814)\end{array}$ & $\begin{array}{l}0.0402^{* * *} \\
(0.00817)\end{array}$ & $\begin{array}{c}0.0328^{* * *} \\
(0.0115)\end{array}$ & $\begin{array}{c}0.0314 * * * \\
(0.0117)\end{array}$ \\
\hline taxrevenue $_{i t}$ & & & $\begin{array}{c}0.0708 \\
(0.0931)\end{array}$ & $\begin{array}{c}0.0988 \\
(0.0699)\end{array}$ & $\begin{array}{l}0.0253^{*} \\
(0.0138)\end{array}$ \\
\hline income $_{i t}$ & & & $\begin{array}{c}0.254 \\
(0.227)\end{array}$ & $\begin{array}{c}0.224 \\
(0.153)\end{array}$ & $\begin{array}{c}0.0108 \\
(0.0248)\end{array}$ \\
\hline $65_{i t}$ & & & $\begin{array}{l}-1.127 \\
(1.128)\end{array}$ & $\begin{array}{l}0.0320 \\
(0.812)\end{array}$ & $\begin{array}{l}0.0237 \\
(0.142)\end{array}$ \\
\hline $17_{i t}$ & & & $\begin{array}{l}-1.103 \\
(0.723)\end{array}$ & $\begin{array}{l}-0.364 \\
(0.503)\end{array}$ & $\begin{array}{l}-0.0354 \\
(0.267)\end{array}$ \\
\hline pop $_{i t}$ & & & $\begin{array}{l}-0.0533 \\
(0.0478)\end{array}$ & $\begin{array}{l}-0.0305 \\
(0.0363)\end{array}$ & $\begin{array}{r}-0.000952 \\
(0.00150)\end{array}$ \\
\hline Constant & $\begin{array}{c}-0.0871^{* * *} \\
(0.0164)\end{array}$ & $\begin{array}{c}-0.0879^{* * *} \\
(0.0164)\end{array}$ & $\begin{array}{l}-0.173 \\
(0.674)\end{array}$ & $\begin{array}{l}-0.335 \\
(0.473)\end{array}$ & $\begin{array}{l}-0.0492 \\
(0.134)\end{array}$ \\
\hline Time Effects & Yes & Yes & Yes & Yes & Yes \\
\hline Observations & 1,488 & 1,488 & 1,488 & 1,440 & 1,440 \\
\hline R-squared & 0.066 & 0.066 & 0.079 & 0.240 & \\
\hline $\begin{array}{l}\text { Number of States } \\
\text { AR1 }\end{array}$ & 48 & 48 & 48 & 48 & $\begin{array}{c}48 \\
-5.256\end{array}$ \\
\hline $\mathrm{p}$-value & & & & & $1.47 \mathrm{e}-07$ \\
\hline AR2 & & & & & -0.440 \\
\hline $\mathrm{p}$-value & & & & & 0.660 \\
\hline Hansen & & & & & 2.052 \\
\hline p-value & & & & & 0.152 \\
\hline
\end{tabular}

Finally, and because environmental expenditures are likely to present a high level of persistence, columns (4) and (5) include the lagged dependent variable. Since the FE estimator is likely to be biased in the presence of fixed effects and a lagged dependent variable, the estimation was preformed with system Generalized Method of Moments (GMM) in column (5) (Arellano and Bover, 1995 and Blundell and Bond, 1998). I use a two-step estimation with a finite sample correction for standard errors (Windmeijer, 2005) and use lags of two or more periods of the dependent variable as instruments. A Hansen test validates the choice of instruments. The results do not change quantitatively, so for the remaining estimations the lagged dependent variable was excluded to avoid problems of endogeneity or bad instruments. The coefficient of tax revenues is positive, suggesting looser budget constraints lead to higher deviations. 
Table 3 presents a number of robustness checks of the results for the main variable of interest. All the estimations include the same control variables as column (3) in Table 2, but their coefficients are omitted for the sake of space, and all are estimated using FE.

Table 3: Robustness: Restricted Sample

\begin{tabular}{|c|c|c|c|c|c|}
\hline Sample & $\begin{array}{l}(1) \\
\text { Full }\end{array}$ & $\begin{array}{c}(2) \\
\text { Restricted }\end{array}$ & $\begin{array}{c}(3) \\
\text { Dem }\end{array}$ & $\begin{array}{c}(4) \\
\text { No Ideo }\end{array}$ & $\begin{array}{c}(5) \\
\text { Competition }\end{array}$ \\
\hline elyear $_{i t}$ & $\begin{array}{c}0.0386 * * * \\
(0.00855)\end{array}$ & $\begin{array}{c}0.0686^{* * *} \\
(0.0153)\end{array}$ & $\begin{array}{c}0.0626^{* * *} \\
(0.0145)\end{array}$ & $\begin{array}{c}0.0361^{* * *} \\
(0.00853)\end{array}$ & $\begin{array}{c}0.0335^{* * *} \\
(0.0108)\end{array}$ \\
\hline Time Effects & Yes & Yes & Yes & Yes & Yes \\
\hline $\begin{array}{l}\text { State Time } \\
\text { Trend }\end{array}$ & Yes & & & & \\
\hline Observations & 1,488 & 514 & 821 & 1,466 & 929 \\
\hline R-squared & 0.135 & 0.112 & 0.142 & 0.076 & 0.100 \\
\hline Number of states & 48 & 37 & 48 & 48 & 48 \\
\hline
\end{tabular}

The first column presents the coefficient for the regression including statespecific time trends, showing the result is robust to this inclusion. The following columns restrict the sample. First, the theoretical model predicts politicians that can be in office for two terms have an incentive to perform pork barrel policies in their first term. Thus in column (2) the sample is restricted to cover only the first term limit in states with a two term limit. The coefficient remains significant and is much larger for the restricted sample. Third, the sample is additionally restricted to cover only democratic incumbents, who are more likely to be credible (or effective) when performing pork as signal of their preference towards the environment. Finally, if re-election is in fact driving these distortionary policies, then we should see that the results are maintained when restricting our attention to elections less likely to be decided on the basis of ideology and more competitive elections. For the former the sample is restricted to elections where the democratic share of vote was larger than 0.25 and smaller than 0.75 , while for the latter it is restricted to cover elections if the index of political competition is larger than $-0.7 \%$, the average value the indicator takes over the sample, or more. Columns (3)-(5) show the results are maintained, and in some cases larger in the restricted sample. However, only the result in column (3) is statistically different from that of the unrestricted sample.

Table 4 presents the results of the predictions of the model regarding features that increase incentives for pork barrel with signaling purposes. 
Table 4: Dispersion, Re-election and Discounting

\begin{tabular}{|c|c|c|c|c|}
\hline Sample & $\begin{array}{l}(1) \\
\text { Full }\end{array}$ & $\begin{array}{c}(2) \\
\text { Democrats }\end{array}$ & $\begin{array}{l}(3) \\
\text { Full }\end{array}$ & $\begin{array}{c}(4) \\
\text { No Lame } \\
\end{array}$ \\
\hline elyear $_{i t}$ & $\begin{array}{c}0.0292 \\
(0.0275)\end{array}$ & $\begin{array}{c}0.121^{* * *} \\
(0.0394)\end{array}$ & $\begin{array}{c}0.0412^{* * *} \\
(0.0104)\end{array}$ & $\begin{array}{c}0.0347^{* *} \\
(0.0149)\end{array}$ \\
\hline disp $_{i} \times$ elyear $_{i t}$ & $\begin{array}{c}0.0119 \\
(0.0276)\end{array}$ & $\begin{array}{c}-0.0619^{*} \\
(0.0362)\end{array}$ & & \\
\hline lame $_{i t}$ & & & $\begin{array}{c}0.0704^{* * *} \\
(0.0209)\end{array}$ & \\
\hline lame $_{i t} \times$ elyear $_{i t}$ & & & $\begin{array}{c}0.00409 \\
(0.0173)\end{array}$ & \\
\hline limit $_{i t}$ & & & & $\begin{array}{l}-0.0316 \\
(0.0283)\end{array}$ \\
\hline lame $_{i t} \times$ elyear $_{i t}$ & & & & $\begin{array}{c}0.0262 \\
(0.0207)\end{array}$ \\
\hline taxrevenue $_{i t}$ & $\begin{array}{c}0.0703 \\
(0.0933)\end{array}$ & $\begin{array}{c}0.185 \\
(0.187)\end{array}$ & $\begin{array}{c}0.0608 \\
(0.0970)\end{array}$ & $\begin{array}{c}0.0694 \\
(0.0977)\end{array}$ \\
\hline income $_{i t}$ & $\begin{array}{c}0.254 \\
(0.227)\end{array}$ & $\begin{array}{c}0.180 \\
(0.384)\end{array}$ & $\begin{array}{c}0.286 \\
(0.233)\end{array}$ & $\begin{array}{c}0.288 \\
(0.270)\end{array}$ \\
\hline $65_{i t}$ & $\begin{array}{l}-1.121 \\
(1.127)\end{array}$ & $\begin{array}{l}-1.528 \\
(2.260)\end{array}$ & $\begin{array}{l}-1.294 \\
(1.165)\end{array}$ & $\begin{array}{c}-2.606^{* *} \\
(1.161)\end{array}$ \\
\hline $17_{i t}$ & $\begin{array}{l}-1.102 \\
(0.723)\end{array}$ & $\begin{array}{c}-3.773^{* * *} \\
(1.245)\end{array}$ & $\begin{array}{l}-1.117 \\
(0.753)\end{array}$ & $\begin{array}{l}-0.861 \\
(0.870)\end{array}$ \\
\hline pop $_{i t}$ & $\begin{array}{l}-0.0535 \\
(0.0479)\end{array}$ & $\begin{array}{r}-0.0248 \\
(0.112)\end{array}$ & $\begin{array}{l}-0.0562 \\
(0.0500)\end{array}$ & $\begin{array}{l}-0.0532 \\
(0.0482)\end{array}$ \\
\hline Constant & $\begin{array}{l}-0.175 \\
(0.675)\end{array}$ & $\begin{array}{c}0.749 \\
(1.056)\end{array}$ & $\begin{array}{l}-0.249 \\
(0.698)\end{array}$ & $\begin{array}{l}-0.173 \\
(0.784)\end{array}$ \\
\hline Time Effects & Yes & Yes & Yes & Yes \\
\hline Observations & 1,488 & 821 & 1,488 & 1,100 \\
\hline R-squared & 0.080 & 0.143 & 0.102 & 0.097 \\
\hline Number of states & 48 & 48 & 48 & 47 \\
\hline
\end{tabular}

In column (1) the coefficient for the dispersion index times the election dummy, disp $_{i} \times$ elyear $_{i t}$, is not statistically significant. However, restricting the sample to include only democrat incumbents, who are more likely to signal a preference for the environment, it becomes negative and statistically significant at a $10 \%$ level. It means that in election years and for states with democrat incumbents, states with higher ideological dispersion than the average receive less environmental expenditures relative to those less dispersed, which indicates that incumbents choose to use their budget for other types of spending. The dispersion index is dropped out of the estimation, as it is not time variant. Column (3) tests the "lame duck" hypothesis. The results show that although in their last term incumbents 
tend to spend more,${ }^{23}$ the hypothesis that politicians that are "lame ducks" spend less in the year before the election as compared to those that can be re-elected is not confirmed: the coefficient for lame $_{i t} \times$ elyear $_{i t}$ is not statistically significant. Finally, column (4) reports results for the effect of term limits. The model predicts that term limits reduce the size of the election year distortion, even when they are not binding, thus the sample was cut to include only politicians that were not on their last term. The coefficient of interest is not statistically significant, meaning that politicians do not behave differently in election years if there are term limits implemented in their state. However, since in 27 out of 35 states with term limits the politicians can still be re-elected at a future point, the existence of term limits might not be a good proxy for the politician's time horizon.

Lastly, in order to verify if the results are driven by an increase in all expenditures in election years the analysis was repeated using as the dependent variable the deviation in environmental expenditures as a percentage of total spending, as well as the level of environmental expenditures as a percentage of total spending. The analyses were performed for the restricted sample of the first term in office in states with two term limits, as well as for democrat incumbents, and are presented in Annex C. The positive and significant coefficient for the election year dummy is maintained. On the contrary, the analysis using as the dependent variable total expenditures per capita there is not a significant impact of the election year dummy.

\section{Conclusion}

This paper presents evidence of the existence of pork barrel spending with signaling purposes. A simple model of electoral competition derives conditions under which pork arises in equilibrium for an incumbent to signal preferences for different issues, for which groups in the population care about differently. The resulting conditions are tested for the case of US state environmental expenditures. Environmental issues are likely to be subject to electoral manipulation since they elicit strong preferences from particular subgroups. The empirical analysis shows some support for the theoretical model. There are systematic increases in environmental spending in years before election across states relative to a politician's average choices. These are smaller when the environmentally biased groups are more ideologically dispersed. Additionally, these distortions are visible when restricting our

\footnotetext{
${ }^{23}$ This is consistent with the work of List and Sturm (2006).
} 
attention to elections that are less likely to be decided on the basis of ideology and close elections.

These results have important implications for the theoretical literature on politically driven policy distortions, as well as for governance discussions. First, I present empirical evidence of the signaling motive for pork barrel across issues and not geographic groups. To the best of my knowledge no study has shown this before. This allows to corroborate the assumptions made in several theoretical studies. Second, the fact that more homogeneous groups are targeted more often has implications for the literature on the formation and influence of special interest groups. It suggests that groups that are organized around ideology will be more able to attract benefits from politicians seeking re-election. Finally, the results show that issues that elicit strong preferences from the electorate are prone to distortions to get electoral advantage, through the signaling mechanism. This makes them particularly subject to electoral cycle variations. In particular for environmental policy, which requires continued action across time in order to be efficient, this has important implications. Namely, mechanisms restraining the discretionary power of politicians that limit the size of electorally driven cycles could increase the efficiency of environmental policy, by protecting it from electoral incentives.

\section{References}

ABC News, Stanford University, and Time Magazine (2006): "ABC News Stanford University Time Magazine Environment Poll 1, March 2006," .

ABC News, Washington Post, and Stanford University (2007): "ABC News Washington Post Stanford University Global Warming Poll, April 2007," .

Ansolabehere, S. And J. M. Snyder JR (2002): "The incumbency advantage in US elections: An analysis of state and federal offices, 19422000," Election Law Journal, 1, 315-338.

Arellano, M. And O. Bover (1995): "Another look at the instrumental variable estimation of error-components models," Journal of econometrics, 68, 29-51.

Besley, T. And A. CAse (1995): "Does electoral accountability affect 
economic policy choices? Evidence from gubernatorial term limits," The Quarterly Journal of Economics, 110, 769-798.

Besley, T. And S. CoAte (1997): "An Economic Model of Representative Democracy," The Quarterly Journal of Economics, 112, 85-114.

Blundell, R. AND S. Bond (1998): "Initial conditions and moment restrictions in dynamic panel data models," Journal of econometrics, 87, $115-143$.

Bouton, L., P. Conconi, F. Pino, And M. Zanardi (2014): "Guns and Votes," Working Paper 20253, National Bureau of Economic Research.

Brender, A. And A. Drazen (2005): "Political budget cycles in new versus established democracies," Journal of Monetary Economics, 52, 12711295.

Calvert, R. L. (1985): "Robustness of the multidimensional voting model: Candidate motivations, uncertainty, and convergence," American Journal of Political Science, 69-95.

CBS News, Inter-university Consortium for Policical Social Research, and The New York Times (1984): "CBS News New York Times National Surveys, 1983," .

Downs, A. (1957): An Economic Theory of Democracy, Harper Collins, New York.

Drazen, A. And M. Eslava (2010): "Electoral manipulation via voterfriendly spending: Theory and evidence," Journal of Development Economics, 92, 39-52.

_ (2012): "Programatic Targeting," Mimeo.

Erikson, R. S., M. B. MacKuen, and J. A. Stimson (2000): "Bankers or peasants revisited: economic expectations and presidential approval," Electoral Studies, 19, 295-312.

Evans, D. (2004): Greasing the Wheels: Using Pork Barrel Projects to Build Majority Coalitions in Congress, Cambridge University Press.

Fredriksson, P. G., L. Wang, and K. A. Mamun (2011): "Are politicians office or policy motivated? The case of US governors' environmental policies," Journal of Environmental Economics and Management, 62, 241-253. 
Hicken, A. And J. W. Simmons (2008): "The Personal Vote and the Efficacy of Education Spending," American Journal of Political Science, $52,109-124$.

Hillstrom, K. And L. Hillstrom (2010): US environmental policy and politics: a documentary history, $\mathrm{Cq} \mathrm{Pr}$.

LAKE, L. M. (1983): "The environmental mandate: activists and the electorate," Political Science Quarterly, 215-233.

Lewis-Beck, M. (1990): Economics and Elections: The Major Western Democracies, University of Michigan Press.

List, J. A. And D. M. Sturm (2006): "How Elections Matter: Theory and Evidence from Environmental Policy," The Quarterly Journal of Economics, 121, 1249-1281.

Lizzeri, A. And N. Persico (2001): "The Provision of Public Goods under Alternative Electoral Incentives," American Economic Review, 91, 225-239.

Lockerbie, B. (1992): "Prospective Voting in Presidential Elections, 19561988," American Politics Research, 20, 308-325.

McGann, A. J., W. Koetzle, and B. Grofman (2002): "How an ideologically concentrated minority can trump a dispersed majority: nonmedian voter results for plurality, run-off, and sequential elimination elections," American Journal of Political Science, 134-147.

Morelli, M. And R. VAn Weelden (2013): "Re-Election Through Division," Department of Economics Discussion Paper Series 1314-02, University of Columbia.

Nordhaus, W. D. (1975): "The Political Business Cycle," The Review of Economic Studies, 42, 169-190.

Osborne, M. J. And A. Slivinski (1996): "A Model of Political Competition with Citizen-Candidates," The Quarterly Journal of Economics, $111,65-96$.

Persson, T. and G. Tabellini (1999): "The size and scope of government:: Comparative politics with rational politicians," European Economic Review, 43, 699-735. 
Rogoff, K. (1990): "Equilibrium Political Budget Cycles," American Economic Review, 80, 21-36, copyright 1990 by the American Economic Association. Posted by permission. One copy may be printed for individual use only.

Rogoff, K. And A. Sibert (1988): "Elections and Macroeconomic Policy Cycles," Review of Economic Studies, 55, 1-16.

UdALL, S. L. (1987): "Local electoral clout," Environment, 29, 2-3.

WindmeiJeR, F. (2005): "A finite sample correction for the variance of linear efficient two-step GMM estimators," Journal of econometrics, 126, $25-51$.

\section{Appendix}

\section{A Political Economic Equilibrium}

Proof of Proposition 1

Denoting the targeted group $j$, voters in all groups update their beliefs that the politician is of types $k$, and symmetrically $j$, according to:

$$
\operatorname{Pr}\left(I=k \mid q_{t}^{P B}\right)=\frac{\operatorname{Pr}\left(q_{t}^{P B} \mid I=i\right) \cdot \lambda^{i}}{\operatorname{Pr}\left(q_{t}^{P B} \mid I=k\right) \cdot \lambda^{k}+\operatorname{Pr}\left(q_{t}^{P B} \mid I=-k\right)\left(1-\lambda^{k}\right)}
$$

with $i=\{k, j\}$.

To solve for the equilibrium, I first assume that the incumbent has an incentive to perform the pork barrel policy, and then check whether this is true. So $\operatorname{Pr}\left(q_{t}^{P B} \mid I=k\right)=1$ and $\operatorname{Pr}\left(q_{t}^{P B} \mid I=-k\right)=\frac{\lambda^{j}}{\lambda^{j}+\lambda^{-j-k}}$. Substituting in the previous expression, we have that for voters in group $k$, and symmetrically for those of group $j$ :

$$
\varepsilon^{k}=\varphi^{k} \mu_{k} g_{k, t+1}
$$

where

$$
\varphi^{k}=\frac{\lambda^{k}\left[1-\lambda^{k}-\left(1-\lambda^{k}\right) \frac{\lambda^{j}}{\lambda^{j}+\lambda^{-k-j}}\right]}{\lambda^{k}+\left(1-\lambda^{k}\right) \frac{\lambda^{j}}{\lambda^{j}+\lambda^{-k-j}}}>0
$$


Once again, for the group whose preferred issue is not spent on, $\varepsilon^{-k-j}=$ $-\lambda_{-k-j} \mu g_{-k-j, t+1}$. Substituting in the re-election probabilities we have that the difference in re-election probabilities for an incumbent of type $k$ of performing or not pork barrel by targeting group $j$ is given by:

$$
\frac{z}{\sum_{i=1}^{3} d^{i}}[d^{k} \mu_{k} g_{k, t+1} \underbrace{\frac{\left(\lambda^{k}-1\right) \frac{\lambda^{j}}{\lambda^{k}+\left(1-\lambda^{k}\right) \frac{\lambda^{j}}{\lambda^{j}+\lambda^{-k-j}}}}{I}-\pi_{q_{t}^{\overline{P B}}}^{I}=(\mathrm{A} .4)}_{A}
$$

Since $A$ is negative and $B$ is positive, and $g_{k, t+1}=g_{j, t+1}$, whether (A.4) is positive or negative depends solely on the ordering of densities and the intensity of preferences given by $\mu_{i}$. When the politician has a preference for the group with the highest density's preferred issue, that is, $k=2$, for (A.4) to be positive and so pork barrel to be effective $\mu_{1}-\mu_{2}$ or $\mu_{3}-\mu_{2}$ has to be large enough to compensate the fact that $d_{1}, d_{3}<d_{2}$.

Substituting equation (A.4) into equation (10), the condition under which the strategy $q_{t}^{P B}$ constitutes an equilibrium is given by:

$$
\beta\left[\left(\frac{z}{\sum_{i=1}^{3} d^{i}}\left[d^{k} \mu_{k} g_{k, t+1} A+d^{j} \mu_{j} g_{j, t+1} B\right]\right)\left(\left[1-\lambda^{k}\right] \mu_{k} g_{k, t+1}+\gamma\right)\right]
$$




\section{B Survey Description}

The data used to create the variables measuring ideological dispersion and environmental bias at the state level were collected from four surveys. All the surveys were acceded through Inter-university Consortium for Political and Social Research (ICPSR) and I used only surveys that included both questions measuring preferences towards the environment and ideology. The first two were conducted by CBS News and New York Times, respectively in April and June of 1983. They were a part of a larger set of surveys performed throughout the year to collect the electorate's views on several subjects (CBS News et al., 1984). To create the environmental preference index I used the response to whether the environment was the most important (or second most important) problem at the time. To create the ideological dispersion I used the respondents' self classification into Liberal, Moderate, Conservative, or Does Not Think in Those Terms. I re-classified the latter as "Moderate" voters, and calculated the standard deviation. The third was conducted by ABC News, Stanford University, and Time Magazine in March 2006 (ABC News et al., 2006) and the fourth by ABC News, The Washington Post, and Stanford University in April 2007 (ABC News et al., 2007). To create the environmental index I used the response to the question of how important the respondent considers respectively the environment and global warming, on a scale of 1 to 5 , as well as other similar questions. The same ideological classification was used. The total number of observations in the four surveys put together is 4824 .

The figures below map the resulting measures. Fig. B.1 maps the environmental bias by state and fig. B.2 the ideological dispersion of environmentally biased voters as the share of total state environmental dispersion. 
Figure B.1: Environmental Bias

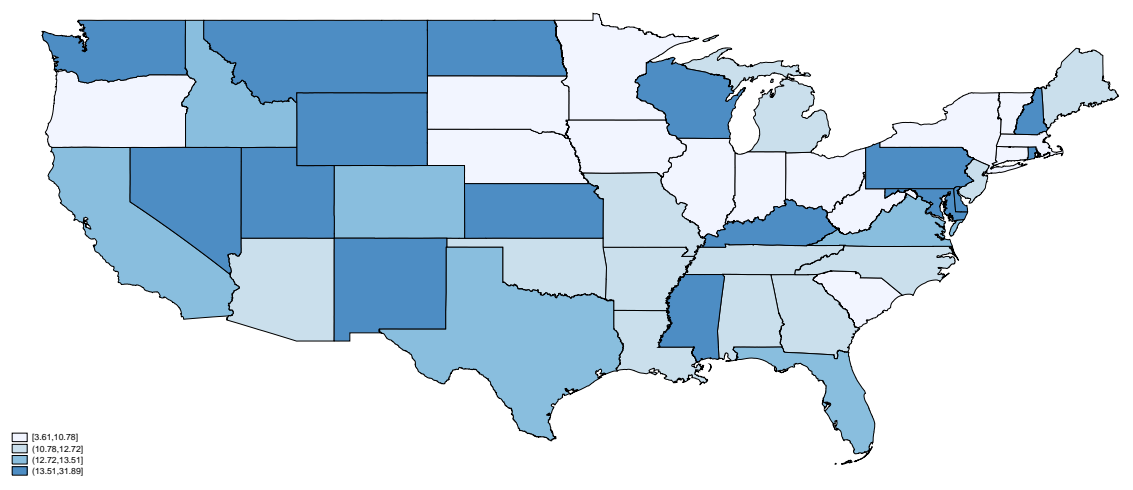

Figure B.2: Ideological Dispersion Index

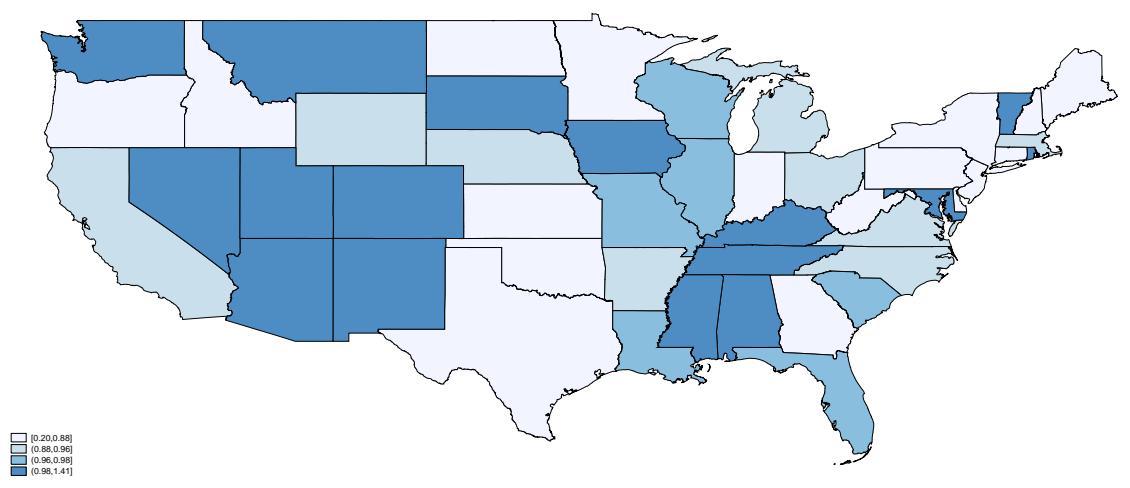




\section{Other Robustness Checks}

Table C.1: Robustness: Different Dependent Variable

\begin{tabular}{|c|c|c|c|c|c|c|}
\hline \multirow[b]{2}{*}{ Sample } & \multicolumn{2}{|c|}{ Deviation Percentage } & \multicolumn{2}{|c|}{ Total Expenditures } & \multirow{2}{*}{$\begin{array}{c}\text { Environment } \\
(5) \\
\text { Democrat }\end{array}$} & \multirow{2}{*}{$\begin{array}{c}\text { Percentage } \\
(6) \\
\text { Restricted }\end{array}$} \\
\hline & $\begin{array}{c}(1) \\
\text { Democrat }\end{array}$ & $\begin{array}{c}(2) \\
\text { Restricted }\end{array}$ & $\begin{array}{c}(3) \\
\text { Democrat }\end{array}$ & $\begin{array}{c}(4) \\
\text { Restricted }\end{array}$ & & \\
\hline elyear $_{i t}$ & $\begin{array}{l}0.0548^{*} \\
(0.0302)\end{array}$ & $\begin{array}{l}0.0592^{*} \\
(0.0348)\end{array}$ & $\begin{array}{c}-0.000922 \\
(0.00373)\end{array}$ & $\begin{array}{c}0.00140 \\
(0.00454)\end{array}$ & $\begin{array}{c}0.0762^{* *} \\
(0.0341)\end{array}$ & $\begin{array}{c}0.0748^{* *} \\
(0.0289)\end{array}$ \\
\hline Time Effects & Yes & Yes & Yes & Yes & Yes & Yes \\
\hline Observations & 821 & 514 & 821 & 514 & 821 & 514 \\
\hline R-squared & 0.079 & 0.069 & 0.912 & 0.936 & 0.112 & 0.090 \\
\hline Number of states & 48 & 37 & 48 & 37 & 48 & 37 \\
\hline
\end{tabular}

Robust standard errors clustered by state. P-values in parentheses.

Significance level at which the null is rejected: $* * * 1 \%,{ }^{* *} 5 \%,{ }^{*} 10 \%$. 